Br Heart $\mathcal{F} 1986 ; 56: 377-9$

Case reports

\title{
Angioplasty of an occluded left anterior descending coronary artery: usefulness of retrograde opacification of the distal part of the occluded vessel via the contralateral coronary artery in positioning the balloon catheter
}

\author{
G GROLliER, PH COMMEAU, J C POTIER \\ From the Service de Réanimation et Soins Intensifs de Cardiologie, CHU Côte de Nacre, Caen, France
}

SUMMARY A 59 year old man was admitted to hospital with a non-transmural anterior myocardial infarction. Recurrent angina pectoris eight days after the initial infarction was investigated by cardiac catheterisation, which showed moderate anterior hypokinesis and proximal occlusion of the left anterior descending coronary artery. The distal part of this vessel was opacified via collaterals from the right coronary artery. Percutaneous transluminal coronary angioplasty was attempted during the same catheterisation; good positioning of the balloon catheter was confirmed by the use of retrograde opacification of the distal part of the left anterior descending coronary artery via the collateral vessels and dilatation was safely achieved.

Opacification of the contralateral coronary artery may be a useful and safe positioning of guide wire system or balloon dilatation catheter when dilatation of a totally occluded coronary artery is attempted.

Use of a movable guide wire system facilitates successful percutaneous transluminal coronary angioplasty when the coronary artery is occluded. When collateral vessels, which usually arise from the contralateral coronary artery, are present the myocardium may remain viable despite a coronary occlusion. Such vessels also allow visualisation of the distal part of the occluded vessel. This retrograde opacification of the occluded vessel may be useful for the safe positioning of either the guide wire or the balloon catheter before inflation. We report the retrograde visualisation of an occluded left anterior descending coronary artery via collateral vessels from the right coronary artery. This allowed good positioning of the balloon catheter and

Requests for reprints to Dr G Grollier, Service de Soins Intensifs et Réanimation de Cardiologie, CHU Côte de Nacre, 14040 Caen Cedex, France. safe percutaneous transluminal coronary angioplasty.

\section{Case report}

A previously healthy 59 year old patient was admitted to the coronary care unit in August 1985 with prolonged chest pain. The patient had no previous history of coronary disease. Examination of the heart was normal and the electrocardiogram showed ST segment depression in the anterior leads from V3 to V6 and in the inferior leads but without pathological $Q$ wave. Echocardiographic examination showed a moderate anterior hypokinesia. Chest pain and ST segment depression persisted despite sublingual and intravenous nitrates. Peak plasma concentration of creatine kinase was $850 \mathrm{U} / 1$ (creatine kinase MB 8\%) twelve hours after admission and the chest pain resolved. Serial electrocardiograms did not show 


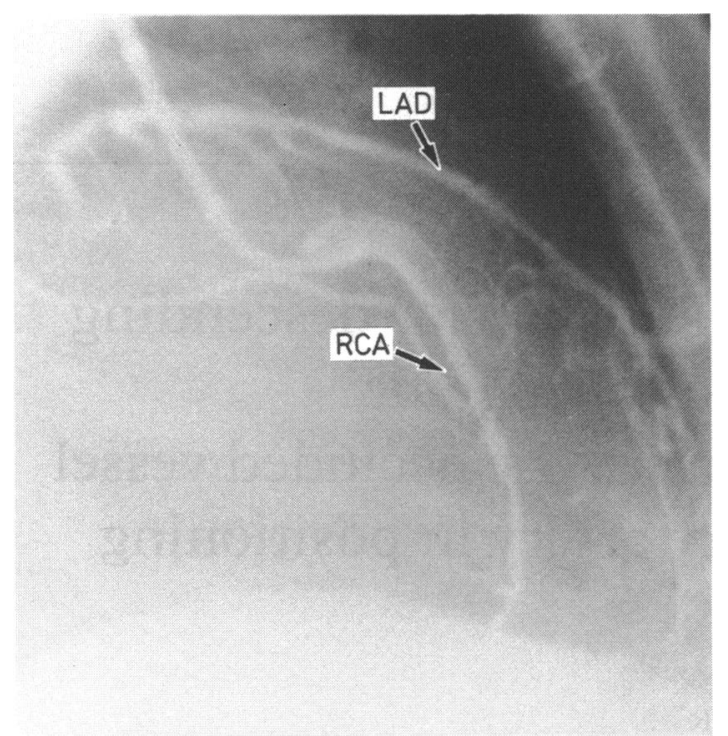

Fig 1 Angiography of the right coronary artery produced opacification of the distal part of the left anterior descending coronary artery ( $L A D)$ via collateral vessels arising from the right coronary artery $(R C A)$.

any abnormal $Q$ waves and the ST segment abnormalities completely regressed. A non-transmural anterior myocardial infarction was diagnosed. Because the patient later had spontaneous recurrent chest pain with ST segment depression in the elec-

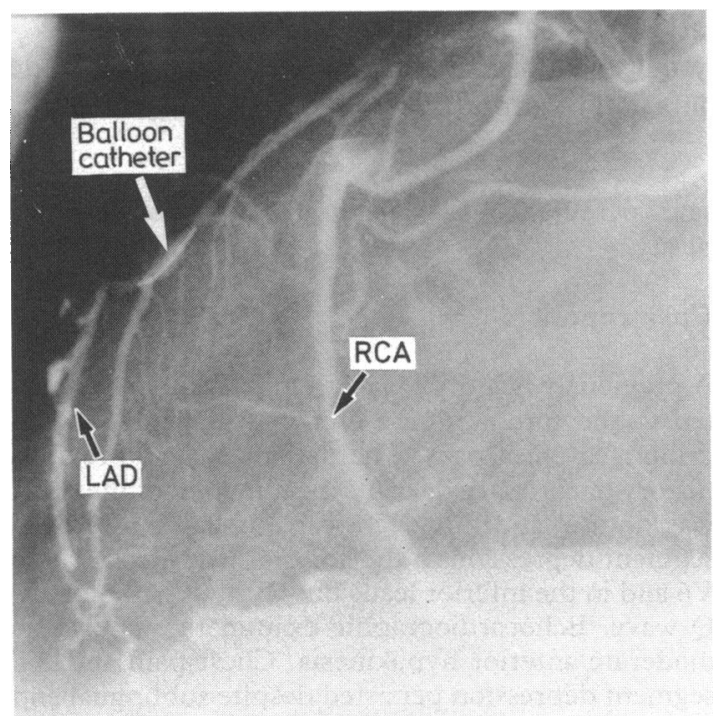

Fig 2 Position of the balloon dilatation catheter demonstrated by the retrograde opacification produced by contrast coming from the right coronary artery via collateral vessels. trocardiographic anterior leads a cardiac catheterisation was performed eight days after admission. This showed impaired left ventricular function with anterior hypokinesia and an ejection fraction of $45 \%$. The left anterior descending coronary artery was occluded at the origin of the first septal perforator. During angiography of the right coronary artery there was a rapid retrograde filling of the left anterior descending coronary artery through large collateral vessels (fig 1 ). Coronary angioplasty was attempted from the right femoral approach with a 9 French Judkins-type guiding catheter and $3 \mathrm{~mm}$ balloon dilatation catheter. Simultaneous opacification of the right coronary artery obtained with a 8 French Judkins catheter from the left femoral approach allowed the distal part of the left anterior descending coronary artery to be visualised and the balloon dilatation catheter to be well positioned in the occluded artery (fig 2). Angioplasty was then performed safely and without difficulty on the mid and proximal part of the left anterior descending coronary artery. Chest pain did not recur after the procedure.

\section{Discussion}

Percutaneous transluminal coronary angioplasty during the acute stage of myocardial infarction (with or without intracoronary or intravenous fibrinolysis) allows prompt recanalisation in a high proportion of cases even when there is occlusion of the infarct associated coronary artery. ${ }^{1-3}$ According to Pepine $e t a l^{2}$ the reason for the high success rate in these circumstances is that penetration of the balloon catheter or the movable guide wire through the occluded vessel is easier than in chronic angina because the material causing occlusion (both old and fresh thrombus and other mechanical elements) is softer and more easily dilated at low pressures. In patients with acute myocardial infarction visualisation of the distal part of the occluded coronary artery via collateral vessels from the contralateral vessel is rare. ${ }^{4}$ Conversely patients with chronic coronary artery obstruction and preservation of myocardial function often have an important collateral flow arising from the ipsilateral or contralateral coronary arteries or both. Elective percutaneous transluminal coronary angioplasty of a totally occluded coronary artery not associated with myocardial infarction is equally feasible. ${ }^{56}$ The primary success rate is about $54 \%$ (conventional stenoses $85 \%),{ }^{6}$ but it varies according to the duration of occlusion (success rate $65 \%$ when the occlusion is estimated to have been present for $\leqslant$ eight weeks and $44 \%$ for $>$ eight weeks) and whether there is a "functionally occluded vessel" that is not totally 
occluded or "total vessel occlusion." Contrast clears from the collateral vessels immediately after successful percutaneous transluminal coronary angioplasty. ${ }^{6}$ Safe coronary angioplasty needs good visualisation of the coronary artery that is to be dilated and for this reason it may be difficult to position the balloon dilatation catheter when the vessel is totally occluded. Like MacDonald and Feldman ${ }^{7}$ we found that good opacification of the postocclusive part of the coronary artery was obtained via the contralateral vessel. We agree with the previous report ${ }^{7}$ that retrograde distal opacification of the occluded coronary artery via a collateral vessel is useful for good positioning of the guide wire and the balloon catheter during percutaneous transluminal coronary angioplasty.

\section{References}

1 Hartzler GO, Rutherford BD, McConahay DR, et al. Percutaneous transluminal coronary angioplasty with and without thrombolytic therapy for treatment of acute myocardial infarction. Am Heart $\mathcal{f}$ 1983;106:965-79.

2 Pepine CJ, Prida X, Hill JA, Feldman RL, Conti RC. Percutaneous transluminal coronary angioplasty in acute myocardial infarction. Am Heart $\mathcal{f}$ 1984; 107:820-2.

3 Grollier G, Commeau P, Bories H, Iselin M, Foucault $\mathrm{JP}$, Potier JC. Une alternative possible à l'échec de la fibrinolyse intracoronarienne par voie percutanée: la dilatation endoluminale percutanée. Ann Cardiol Angeiol (Paris) 1984;33:435-9.

4 Hill JA, Feldman RL, MacDonald RG, Pepine CJ. Coronary artery collateral visualization during acute coronary occlusion. Am $\mathcal{f}$ Cardiol 1985;55:1216-8.

5 Serruys PW, Umans GR, vd Brand M, et al. Elective PTCA of totally occluded coronary arteries not associated with acute myocardial infarction: short-term and long-term results. Eur Heart $\mathcal{f}$ 1985;6:2-12.

6 Dervan JP, Baims DS, Cherniles J, Grossman W. Transluminal angioplasty of occluded coronary arteries: use of a movable guide wire system. Circulation 1983;68:776-84.

7 MacDonald RG, Feldman RL. Right coronary angiography during left anterior descending angioplasty: collateral visualization as a guide to balloon positioning. Am $\mathcal{f}$ Cardiol 1985;55:845-7. 